\title{
THE MOLAR TOOTH SIGN AND THE BAT WING APPEARANCE IN JOUBERT SYNDROME
}

Clin Biomed Res. 2018;38(1):96-98

1 Serviço de Radiologia, Hospital de Clínicas de Porto Alegre (HCPA). Porto Alegre, RS, Brasil.

2 Departamento de Medicina Interna, Universidade Federal do Rio Grande do Sul (UFRGS). Porto Alegre, RS, Brasil.

3 Serviço de Genética Médica, Hospital de Clínicas de Porto Alegre (HCPA). Porto Alegre, RS, Brasil.

4 Serviço de Neurologia, Hospital de Clínicas de Porto Alegre (HCPA). Porto Alegre, RS, Brasil.

Corresponding author: Matheus Dorigatti Soldatelli md.soldatelli@gmail.com Serviço de Radiologia, Hospital de Clínicas de Porto Alegre (HCPA) Rua Ramiro Barcelos, 2350 90035-007, Porto Alegre, RS, Brasil.
Matheus Dorigatti Soldatelli ${ }^{1}$, Natália Henz Concatto ${ }^{1}$, Jonas Alex Morales Saute ${ }^{2,3,4}$, Carolina Fischinger Moura de Souza ${ }^{3}$, Juliano Adams Perez ${ }^{1}$, Juliana Ávila Duarte ${ }^{1}$

A 10-year-old female patient was brought to the outpatient clinic with a history of neurodevelopmental delay, gait and limb incoordination, and oculomotor apraxia. According to her parents, the girl had always showed delayed acquisition of motor milestones when compared to other children, which became more evident when she was 8 months old and was not able to sit. She was able to sit by age of 2 , and walked independently, but unsteady, when she was 3.5 years old. She presented with cognitive impairment. Reviewing her history, it became clear that she was hypotonic at birth and subsequently developed gait ataxia in early childhood. She was born to nonconsanguineous parents and there were no other similar cases in her family.

On physical examination, she held her head preferentially in a lateralized position to her right side. She showed gait ataxia in tandem walking, abnormal stance with a positive Romberg's sign, dysmetria, dysdiadochokinesia, diffuse hyperreflexia, bilateral Babinski sign, and oculomotor apraxia. The Wechsler Intelligence Scale for Children-III (WISC-III) demonstrated an IQ of 67 (intellectual disability). There were no other abnormalities on physical examination. Electroencephalogram showed focal paroxysmal discharges of moderate intensity in the posterior parietal-temporal region.

Brain magnetic resonance imaging (MRI) demonstrated agenesis of the cerebellar vermis with a slit in the medial line sparing the two cerebellar hemispheres (Figure 1), lengthening and thickening of the cerebellar peduncles, associated with reduction of the anteroposterior diameter of the mesencephalon, the so-called "molar tooth sign" (MTS) (Figure 2). Morphological alterations in the posterior fossa showed a 4th ventricle with a typical "bat wing" appearance (Figure 3). These findings were highly suggestive of Joubert syndrome (JS).

JS is a group of rare genetic conditions characterized by three primary findings: a distinctive cerebellar and brainstem malformation (the MTS), hypotonia in infancy with later development of ataxia, and developmental delay or intellectual disability. Additional findings include abnormal breathing and eye movement patterns. The MTS originates from the association of cerebellar hypo/aplasia, horizontally-oriented and thickened superior cerebellar peduncles, and a deepened interpeduncular fossa. JS may be associated with several abnormalities in other organs, identifying a large spectrum of Joubert syndrome-related disorders (JSRD) ${ }^{1-3}$.

The clinical diagnosis of JS is based on MRI findings and characteristic clinical features. A molecular diagnosis of JS can be established in approximately $62-94 \%$ of individuals with a clinical diagnosis ${ }^{4}$. Treatment for Joubert syndrome is symptomatic and supportive. Infant stimulation and physical, occupational, and speech therapy may benefit some children. Screening for progressive eye, liver, and kidney complications associated with JSRD should be performed on a regular basis ${ }^{5}$. 


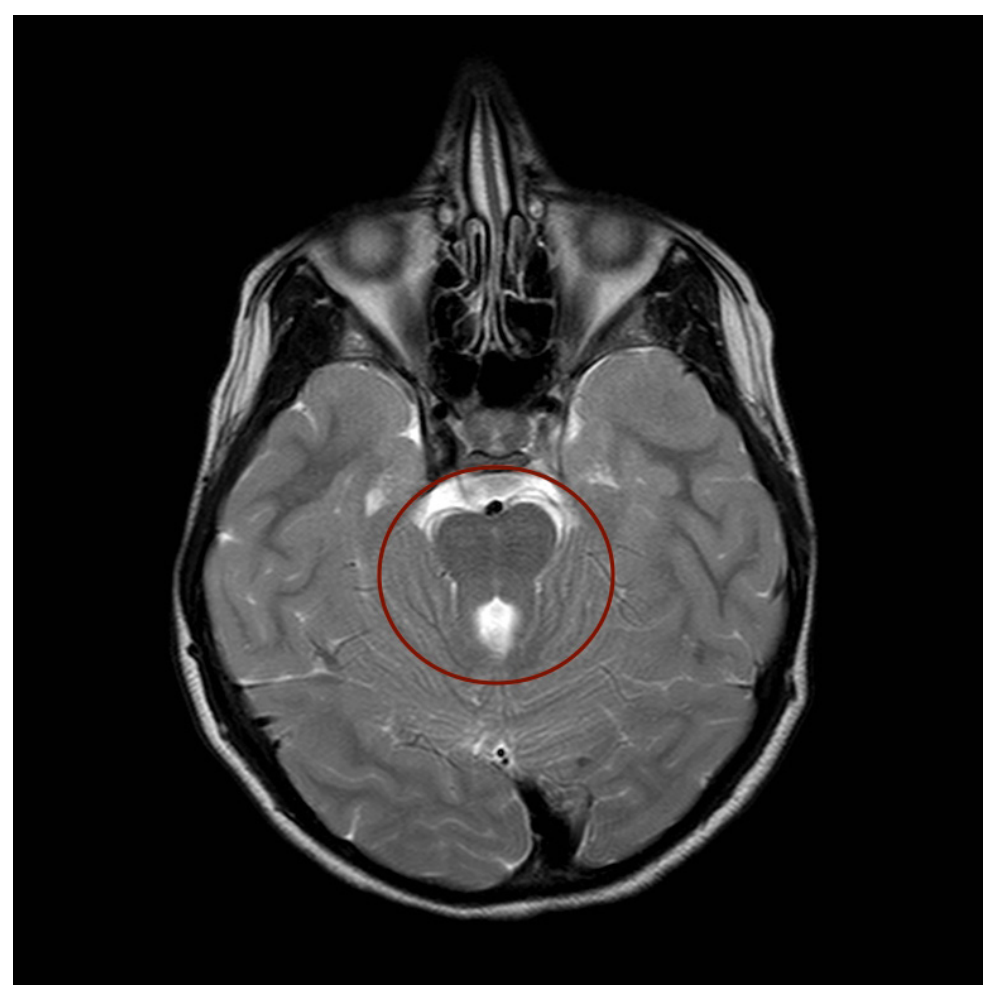

Figure 1: Axial T2 weighted magnetic resonance imaging (MRI) scan of the brain demonstrating lengthening and thickening of the cerebellar peduncles, associated with a reduction of the anteroposterior diameter of the mesencephalon, the so-called "molar tooth sign" (inside the red circle).

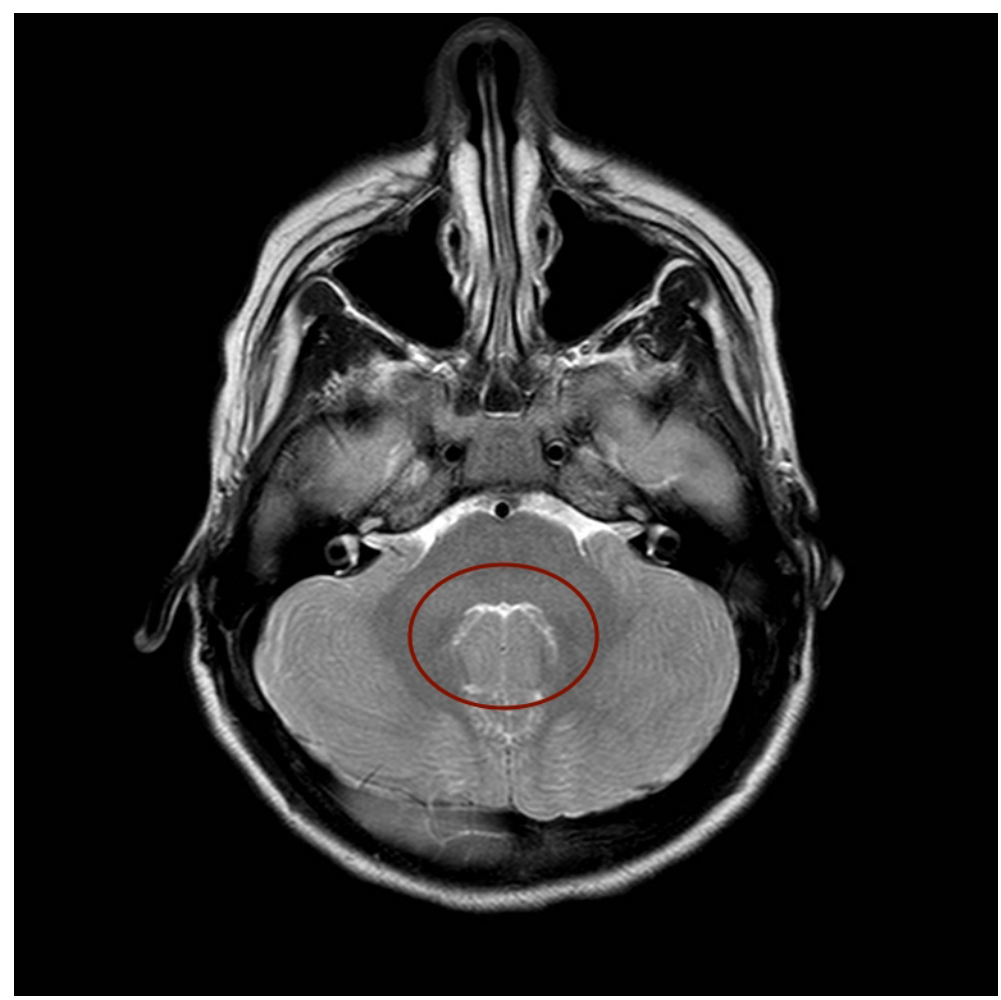

Figure 2: Axial T2 weighted magnetic resonance imaging (MRI) scan of the brain demonstrating the typical "bat wing" morphologic aspect of the 4th ventricle (inside the red circle), agenesis of the cerebellar vermis with a slit in the medial line sparing the two cerebellar hemispheres. 


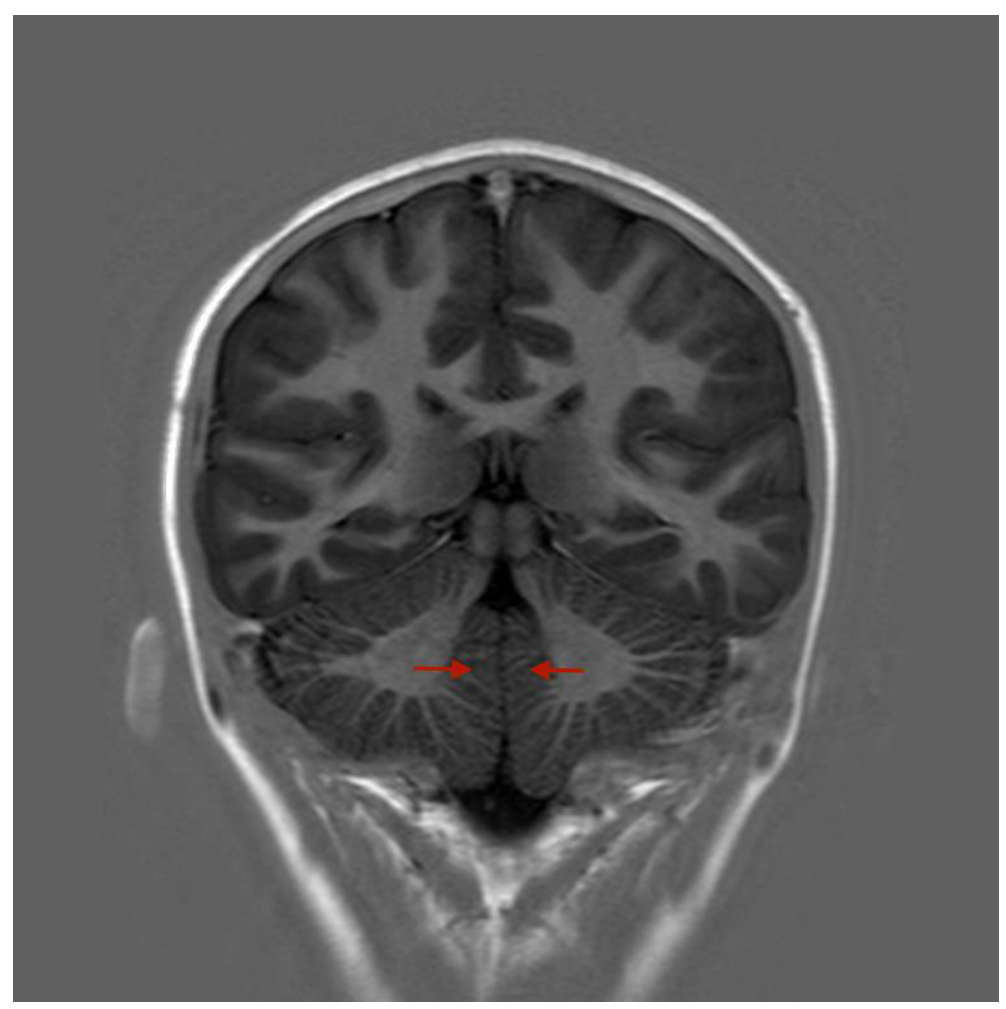

Figure 3: Coronal inversion recovery magnetic resonance imaging (MRI) of the brain demonstrating agenesis of the cerebellar vermis with a slit in the medial line sparing the two cerebellar hemispheres (see red arrows).

\section{Conflicts of Interest}

The authors declare no conflicts of interest.

\section{REFERENCES}

1. Valente EM, Brancati F, Dallapiccola B. The expanding Joubert spectrum. Neuroradiol J. 2007;20(4):421-5. http://dx.doi.org/10.1177/19714009070 2000406.

2. Harrison V, Németh $\mathrm{AH}$. Joubert syndrome and Joubert syndromerelated disorders. In: Kenny TD, Beales PL, editors. Ciliopathies: a reference for clinicians. Oxford: Oxford University Press; 2013. p. 6491.

3. McGraw P. The molar tooth sign. Radiology. 2003;229(3):671-2. http:// dx.doi.org/10.1148/radiol.2293020764.

4. Parisi M, Glass I. Joubert syndrome. In: Adam MP, Ardinger HH, Pagon RA, Wallace SE, Bean LJH, Stephens
K, editors. GeneReviews ${ }^{\circledR}$. Seattle: University of Washington, Seattle; 2017. [cited 2017 June 28]. Available from: https://www.ncbi.nlm.nih.gov/ pubmed/20301500

5. Brancati F, Dallapiccola B, Valente EM. Joubert syndrome and related disorders. Orphanet J Rare Dis. 2010;5(1):20. http://dx.doi. org/10.1186/1750-1172-5-20. 